\title{
Dynamic Analysis of an Infinitely Long Beam Resting on a Kelvin Foundation under Moving Random Loads
}

\author{
Y. Zhao, ${ }^{1}$ L. T. Si, ${ }^{1}$ and H. Ouyang ${ }^{2}$ \\ ${ }^{1}$ State Key Laboratory of Structural Analysis for Industrial Equipment, Faculty of Vehicle Engineering and Mechanics, \\ Dalian University of Technology, Dalian 116023, China \\ ${ }^{2}$ School of Engineering, University of Liverpool, The Quadrangle, Liverpool L69 3GH, UK
}

Correspondence should be addressed to Y. Zhao; yzhao@dlut.edu.cn

Received 27 December 2016; Accepted 27 February 2017; Published 16 March 2017

Academic Editor: Laurent Mevel

Copyright ( 92017 Y. Zhao et al. This is an open access article distributed under the Creative Commons Attribution License, which permits unrestricted use, distribution, and reproduction in any medium, provided the original work is properly cited.

\begin{abstract}
Nonstationary random vibration analysis of an infinitely long beam resting on a Kelvin foundation subjected to moving random loads is studied in this paper. Based on the pseudo excitation method (PEM) combined with the Fourier transform (FT), a closedform solution of the power spectral responses of the nonstationary random vibration of the system is derived in the frequencywavenumber domain. On the numerical integration scheme a fast Fourier transform is developed for moving load problems through a parameter substitution, which is found to be superior to Simpson's rule. The results obtained by using the PEM-FT method are verified using Monte Carlo method and good agreement between these two sets of results is achieved. Special attention is paid to investigation of the effects of the moving load velocity, a few key system parameters, and coherence of loads on the random vibration responses. The relationship between the critical speed and resonance is also explored.
\end{abstract}

\section{Introduction}

Dynamic analysis of a structure subjected to moving loads has always been an important subject for researchers, which has an extensive engineering background [1-5]. To date, various moving load dynamic problems have been studied, for example, as reviewed in [6], from relatively simple problems of vibration of a beam excited by a moving mass and vibration of a rotating shaft under a moving surface load to complicated vehicle-track-bridge interaction problems.

For a moving load problem, even if the load is modelled as a stationary process, the response at an observed point in a structure is nonstationary because of the load's motion in space. Such a problem is obviously different from the nonstationary random vibration which has been widely studied in earthquake engineering. In earthquake engineering the nonstationary random vibration response of a structure is induced by the nonstationary random earthquake input. To date, nonstationary earthquake motion and structural analysis of earthquake response have been extensively investigated
$[7,8]$. However, research into nonstationary random vibration induced by moving random loads is fairly uncommon. In particular, the efficiency in computing dynamic responses of structures under moving random loads is low and thus must be enhanced, which is the motivation of this paper.

In railway engineering, the dynamic interaction between trains and rails can be represented as nonstationary random vibration of an infinitely long beams resting on a Kelvin foundation. The moving load model is more suitable to explore several dynamic aspects of a train-track interaction problem, such as critical speed and resonance characteristics.

For steady-state response of a structure subjected to moving loads, its damping, stiffness, and load velocity are considered important parameters. Achenbach and Sun [9] investigated the responses of a Timoshenko beam of infinite length subjected to a force moving at constant velocity and studied the influence of the damping coefficient and the load velocity on the system responses. Jones et al. [10] presented a model of a track on a layered ground under a moving oscillating load and discussed the effect of the relative 
speeds of the load, the effect of the ground type, and the effect of the embankment on the vertical displacement of the ground. Lin and Trethewey [11] proposed a method for the dynamic analysis of elastic beams subjected to dynamic loads induced by the arbitrary movement of a spring-massdamper system. In addition to the steady-state response of a structure subjected to moving loads, the critical state and stability are another major aspect of a moving load problem. Chen et al. [12] established the dynamic stiffness matrix of an infinite Timoshenko beam on viscoelastic foundation under a harmonic moving load and determined the critical velocities and the resonant frequencies. Dieterman and Metrikine [13, 14] derived expressions of the equivalent stiffness of an elastic half space interacting with a beam with finite width and determined the critical velocities of a constant load moving. Suiker et al. [15] investigated the problem of a moving load on a Timoshenko beam-half plane system and analyzed the subcritical/supercritical states.

The nonlinear dynamics of a structure subjected to moving loads is also studied. Yoshimura et al. $[16,17]$ investigated the deflection of a beam, including the effects of geometric nonlinearity, subjected to moving vehicle loads. Şimşek [18] proposed a method for nonlinear dynamic analysis of a functionally graded beam with pinned-pinned supports subjected to a moving harmonic load on Timoshenko beam theory combined with the von-Kármán's nonlinear straindisplacement relationship. Castro Jorge et al. [19] studied the dynamic response of a beam on nonlinear elastic foundations under moving constant load and carried out parametric analysis of the load intensity and velocity and the foundation's stiffness.

The above-mentioned works focus on deterministic moving load problems. In fact, for the very important problems of dynamic interactions between vehicles and structures, the irregularity of a rail or road surface should be considered in structural design and analysis. There are a number of published papers that cover moving random loads. Bryja and Śniady [20] and Śniady [21] assumed that the force arriving at a bridge as a Poisson process of events and developed an analytical technique to determine the bridge's random vibration response. Chatterjee et al. [22] carried out a continuum analysis for determining the flexural-torsional vibration of a suspension bridge under vehicular movement and the surface irregularity of the bridge pavement was generated from a power spectral density function. Zibdeh [23] studied the random vibration of a simply supported elastic beam under moving random loads with time-varying velocity. Huang and Wang [24] modelled bridges as grillage beam systems and vehicle as a linear multibody model and analyzed the effect of longitudinal grade on the vibration of bridges considering surface roughness. Lombaert et al. [25] built a numerical model of free field traffic-induced vibration during the passage of a vehicle on an uneven road and derived a transfer function between the source and the receiver. Kim et al. [26] proposed a three-dimensional analysis for bridgevehicle interaction in which measured roadway roughness profiles were used. Chang and Liu [27] made deterministic and random vibration analysis of a nonlinear beam on an elastic foundation subjected to a moving load.

In order to evaluate the random vibration responses of a system induced by moving random load the Monte Carlo method is adopted usually in the above-mentioned studies. The samples of irregular profiles, as input excitation of the system, can be generated according to Fourier series with random phases and the statistical responses of the system can be obtained by using a time-domain integration method. The nonlinear behaviour of structures can be also considered by using Monte Carlo method, which is a significant advantage [28]. However, the time-domain method does not yield the frequency-domain characteristics of the nonstationary random vibration of the system in a straightforward and intuitive manner and it is inconvenient to investigate the resonance phenomenon. Moreover, in order to achieve more reliable predictions a large number of samples must be used in Monte Carlo method; thus a more time-consuming analysis has to be performed.

The power spectral method representing the energy distribution with respect to frequencies is a widely accepted method in random vibration field $[29,30]$. For a moving random load problem the frequency-domain method based on the spectral analysis theory of random vibration is extremely attractive for evaluation of the response statistics. However, there are also some difficulties encountered in the practical application of the random vibration theory to moving load problems, such as the following: (1) for a random load moving at constant speed, even though the input load is a stationary random process, the responses of the structure will be a nonstationary process with evolutionary feature due to the load movement. (2) The critical speed of a system is closely related to the structural properties, velocity, and frequency components of the moving load. It is a nearly impossible task to explore the responses under a moving random load using analytical method.

For random vibration analysis of linear systems the PEM is an efficient and accurate algorithm, which has been widely used in the field of earthquake engineering [31-34]. To overcome the above difficulties a hybrid pseudo excitation method-Fourier transform (PEM-FT) is established in this paper. Using PEM-FT the closed-form solution of the evolutionary spectrum (frequency/time) of the systems response is derived, which has a concise expression. Moreover, the computing time of PEM-FT is very short compared with the time-domain Monte Carlo method. Another advantage is that the system's characteristics in frequency domain can be understood intuitively.

The organization of this paper is as follows. Section 2 introduces the dynamic model and governing differential equation for an infinitely long beam resting on a Kelvin foundation subjected to moving random load. Section 3 presents the equation of motion described in the frequencywave number domain and then Green function obtained by using integral-transform method. In Section 4 the PEM-FT is developed to evaluate the nonstationary random vibration responses of the beam. Introducing the substitution of an integration parameter the discrete fast Fourier transform is proposed for the numerical integration, which has a high 


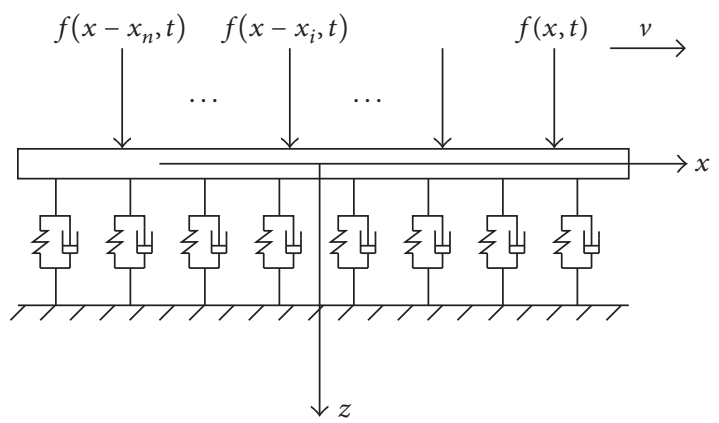

Figure 1: Model of an infinitely long beam resting on a Kelvin foundation under moving random loads.

computational efficiency. Further, the critical velocity of moving load is discussed. In Section 5 the proposed method is verified using Monte Carlo method and the influence of the structural damping, stiffness, and load velocity on random vibration responses is investigated. Finally, the main results of this paper are summarized in Section 6. Although a relatively simple mechanical model is studied in this paper, the theory and the numerical analysis method are applicable to the study of nonstationary vibration of more complex coupled traintrack systems.

\section{Infinitely Long Beam Resting on a Kelvin Foundation under Moving Random Loads}

An Euler-Bernoulli beam resting on a viscoelastic foundation of Kelvin type subjected to a sequence of moving random loads, as shown in Figure 1, is meant to represent a train running on a rail track in an approximate way. In the following derivations and discussions, the initial system is considered as quiescent.

Its governing partial differential equation of motion can be written as

$$
\begin{aligned}
E I & \frac{\partial^{4} w(x, t)}{\partial x^{4}}+K w(x, t)+\eta \frac{\partial w(x, t)}{\partial t}+\bar{m} \frac{\partial^{2} w(x, t)}{\partial t^{2}} \\
& =\sum_{i=1}^{n} f\left(x-x_{i}, t\right)
\end{aligned}
$$

in which $w=w(x, t)$ is the lateral displacement of the beam; $E I$ and $\bar{m}$ are the flexural rigidity and mass per unit length of the beam, respectively; $K$ and $\eta$ are the stiffness and damping of foundation; $\sum_{i=1}^{n} f\left(x-x_{i}, t\right)$ are the loads acting on the beam. If the relative velocity involved is constant, the loads can be expressed further as

$$
\sum_{i=1}^{n} f\left(x-x_{i}, t\right)=\sum_{i=1}^{n} \delta\left(x-v\left(t-t_{i}\right)\right) q\left(t-t_{i}\right)
$$

in which $\delta(\cdot)$ is Dirac delta function; $v$ is load velocity; $q\left(t-t_{i}\right)$ is taken as a stationary random excitation with power spectral density $S_{q q}(\omega)$.
For the steady-state response, the boundary conditions of (1) are given by

$$
\lim _{x \rightarrow \pm \infty} \frac{\partial^{n} w}{\partial x^{n}}=0, \quad n=0,1,2,3, \ldots
$$

Here, (1)-(3) constitute the mathematical model of the moving random load problem.

\section{Green's Function of Structural Dynamic Response in Wavenumber-Frequency Domain}

In mathematical-physics Green's function is an important concept, also known as a source function or an influence function, which describes a field generated by a point source under some boundary conditions and initial conditions [35]. Green's function $G\left(\mathbf{x}, t ; \mathbf{x}_{0}, \tau\right)$ represents the dynamic response at point $\mathbf{x}$ and at time $t$ when the structure is subjected to an impulse at point $\mathbf{x}_{0}$ and at time $\tau$. It is a function which is only dependent on the space distance between source and receiving points, as well as the delay between receiving and triggering time.

The double Fourier transform of a space-time function $g(x, t)$ and its inverse is defined as follows:

$$
\begin{aligned}
\tilde{\tilde{g}}\left(k_{x}, k_{t}\right) & =\int_{-\infty}^{\infty} \int_{-\infty}^{\infty} g(x, t) e^{-j k_{x} x} e^{-j k_{t} t} \mathrm{~d} x \mathrm{~d} t \\
g(x, t) & =\int_{-\infty}^{\infty} \int_{-\infty}^{\infty} \tilde{\widetilde{g}}\left(k_{x}, k_{t}\right) e^{j k_{t} t} e^{j k_{x} x} \mathrm{~d} k_{x} \mathrm{~d} k_{t}
\end{aligned}
$$

in which $j=\sqrt{-1}$.

Replacing the load on the right side of (1) with $\delta(x) \delta(t)$, to represent a unit impulse acting at the origin of the coordinate system and at the initial time instant of $t=0$, and then applying the double Fourier transform yields

$$
E I k_{x}^{4} \widetilde{\widetilde{w}}+K \widetilde{\widetilde{w}}+j \eta k_{t} \widetilde{\widetilde{w}}-\bar{m} k_{t}^{2} \widetilde{\widetilde{w}}=1 .
$$

Equation (5) gives the vertical displacement of the beam in frequency and wavenumber domain, and its solution can be easily obtained as

$$
H\left(k_{x}, k_{t}\right)=\widetilde{\widetilde{w}}_{\bar{q}}\left(k_{x}, k_{t}\right)=\frac{1}{E I k_{x}^{4}+K+j \eta k_{t}-\bar{m} k_{t}^{2}} .
$$

By applying inverse Fourier transform to (6) one can obtain the vertical displacement of the beam under the impulse in physical domain:

$$
\begin{aligned}
& G(x, t ; 0,0)=w_{\bar{q}}(x, t) \\
& \quad=\frac{1}{4 \pi^{2}} \int_{-\infty}^{\infty} \int_{-\infty}^{\infty} H\left(k_{x}, k_{t}\right) e^{j k_{t} t} e^{j k_{x} x} \mathrm{~d} k_{x} \mathrm{~d} k_{t} .
\end{aligned}
$$

Equation (7) gives Green's function of the infinitely long beam resting on a Kelvin foundation, and based on this function 
one can obtain the dynamic response of the beam under any moving load.

\section{Nonstationary Random Vibration of a Structure under Moving Random Load}

4.1. Pseudo Excitation Method for Nonstationary Random Vibration Analysis. It is assumed that the sequence of moving random loads possess the same form of function of $t$ each with a constant time delay as $q\left(t-t_{i}\right)$ in (2). For convenience of derivation, the moving random load sequence is expressed in vector form:

$$
\mathbf{f}(x, t)=\mathbf{A}(x, t) \mathbf{q}(t)
$$

in which

$$
\begin{aligned}
& \mathbf{A}(x, t)=\operatorname{diag}\left[\delta\left(x-v\left(t-t_{1}\right)\right), \delta\left(x-v\left(t-t_{2}\right)\right), \ldots,\right. \\
& \left.\quad \delta\left(x-v\left(t-t_{n}\right)\right)\right] \\
& \mathbf{q}(t)=\left\{q\left(t-t_{1}\right), q\left(t-t_{2}\right), \ldots, q\left(t-t_{n}\right)\right\}^{T} .
\end{aligned}
$$

Applying Green's function the displacement response of the structure under a random load sequence as (8) can be obtained by generalized Duhamel integral as

$$
w(x, t)=\int_{-\infty}^{\infty} \int_{-\infty}^{\infty} \mathbf{G}(x-\zeta, \tau ; 0,0) \mathbf{f}(\zeta, t-\tau) \mathrm{d} \zeta \mathrm{d} \tau
$$

in which

$$
\begin{aligned}
& \mathbf{G}(x-\zeta, \tau ; 0,0)=\left\{G\left(x-\zeta_{1}, \tau_{1} ; 0,0\right),\right. \\
& \left.\quad G\left(x-\zeta_{2}, \tau_{2} ; 0,0\right), \ldots, G\left(x-\zeta_{n}, \tau_{n} ; 0,0\right)\right\},
\end{aligned}
$$

where $\mathbf{G}$ is $1 \times n$ dimension vector.

For a pair of time instants $t_{k}$ and $t_{l}$, the product of response $w\left(x, t_{k}\right)$ with response $w\left(x, t_{l}\right)$ is given by

$$
\begin{aligned}
& w\left(x, t_{k}\right) w\left(x, t_{l}\right) \\
& =\int_{-\infty}^{+\infty} \int_{-\infty}^{+\infty} \int_{-\infty}^{+\infty} \int_{-\infty}^{+\infty} \mathbf{G}\left(x-\zeta_{k}, \tau_{k} ; 0,0\right) \mathbf{f}\left(\zeta_{k}, t_{k}-\tau_{k}\right) \\
& \quad \cdot \mathbf{f}^{T}\left(\zeta_{l}, t_{l}-\tau_{l}\right) \mathbf{G}^{T}\left(x-\zeta_{l}, \tau_{l} ; 0,0\right) \mathrm{d} \zeta_{k} \mathrm{~d} \zeta_{l} \mathrm{~d} \tau_{k} \mathrm{~d} \tau_{l} .
\end{aligned}
$$

Substituting (10) into (12) and applying an expectation operator $E[\cdot]$ to the resultant equation generate the correlation function below:

$$
\begin{aligned}
E & {\left[w\left(x, t_{k}\right) w\left(x, t_{l}\right)\right] } \\
= & \int_{-\infty}^{+\infty} \int_{-\infty}^{+\infty} \int_{-\infty}^{+\infty} \int_{-\infty}^{+\infty} \mathbf{G}\left(x-\zeta_{k}, \tau_{k} ; 0,0\right) \mathbf{A}\left(\zeta_{k}, t_{k}-\tau_{k}\right) \\
& \cdot \mathbf{A}^{T}\left(\zeta_{l}, t_{l}-\tau_{l}\right) \mathbf{G}^{T}\left(x-\zeta_{l}, \tau_{l} ; 0,0\right) \\
& \cdot E\left[\mathbf{q}\left(\zeta_{k}, t_{k}-\tau_{k}\right) \mathbf{q}^{T}\left(\zeta_{l}, t_{l}-\tau_{l}\right)\right] \mathrm{d} \zeta_{k} \mathrm{~d} \zeta_{l} \mathrm{~d} \tau_{k} \mathrm{~d} \tau_{l} .
\end{aligned}
$$

Let $\bar{\tau}_{k}=t_{k}-\tau_{k}$ and $\bar{\tau}_{l}=t_{l}-\tau_{l}$. According to the Wiener-Khintchine theorem, the autocorrelation function of stationary process $\mathbf{q}(t)$ can be expressed as

$$
\begin{aligned}
& E\left[\mathbf{q}\left(\zeta_{k}, t_{k}-\tau_{k}\right) \mathbf{q}^{T}\left(\zeta_{l}, t_{l}-\tau_{l}\right)\right] \\
& =\left[\begin{array}{cccc}
E\left[q\left(\zeta_{k}, \bar{\tau}_{k}-t_{1}\right) q\left(\zeta_{l}, \bar{\tau}_{l}-t_{1}\right)\right] & E\left[q\left(\zeta_{k}, \bar{\tau}_{k}-t_{1}\right) q\left(\zeta_{l}, \bar{\tau}_{l}-t_{2}\right)\right] & \cdots & E\left[q\left(\zeta_{k}, \bar{\tau}_{k}-t_{1}\right) q\left(\zeta_{l}, \bar{\tau}_{l}-t_{n}\right)\right] \\
E\left[q\left(\zeta_{k}, \bar{\tau}_{k}-t_{2}\right) q\left(\zeta_{l}, \bar{\tau}_{l}-t_{1}\right)\right] & E\left[q\left(\zeta_{k}, \bar{\tau}_{k}-t_{2}\right) q\left(\zeta_{l}, \bar{\tau}_{l}-t_{2}\right)\right] & \cdots & E\left[q\left(\zeta_{k}, \bar{\tau}_{k}-t_{2}\right) q\left(\zeta_{l}, \bar{\tau}_{l}-t_{n}\right)\right] \\
\vdots & \ddots & \ddots \\
E\left[q\left(\zeta_{k}, \bar{\tau}_{k}-t_{n}\right) q\left(\zeta_{l}, \bar{\tau}_{l}-t_{1}\right)\right] & E\left[q\left(\zeta_{k}, \bar{\tau}_{k}-t_{n}\right) q\left(\zeta_{l}, \bar{\tau}_{l}-t_{2}\right)\right] & \cdots & E\left[q\left(\zeta_{k}, \bar{\tau}_{k}-t_{n}\right) q\left(\zeta_{l}, \bar{\tau}_{l}-t_{n}\right)\right]
\end{array}\right] \\
& =\int_{-\infty}^{\infty}\left[\begin{array}{cccc}
1 & e^{j \omega\left(t_{1}-t_{2}\right)} & \cdots & e^{j \omega\left(t_{1}-t_{n}\right)} \\
e^{j \omega\left(t_{2}-t_{1}\right)} & 1 & \cdots & e^{j \omega\left(t_{2}-t_{n}\right)} \\
\vdots & \vdots & \ddots & \vdots \\
e^{j \omega\left(t_{n}-t_{1}\right)} & e^{j \omega\left(t_{n}-t_{2}\right)} & \cdots & 1
\end{array}\right] e^{j \omega\left(\bar{\tau}_{k}-\bar{\tau}_{l}\right)} S_{q q}(\omega) \mathrm{d} \omega=\int_{-\infty}^{\infty} \mathbf{Z}(\omega) \mathbf{s s}^{T} \mathbf{Z}^{T}(\omega) \mathrm{e}^{j \omega\left(\bar{\tau}_{k}-\bar{\tau}_{l}\right)} S_{q q}(\omega) \mathrm{d} \omega
\end{aligned}
$$

in which

$$
\begin{aligned}
\mathbf{Z}(\omega) & =\operatorname{diag}\left[e^{j \omega t_{1}}, e^{j \omega t_{2}}, \ldots, e^{j \omega t_{n}}\right], \\
\mathbf{s} & =\{1,1, \ldots, 1\}^{T} .
\end{aligned}
$$

Substituting (14) into (13) yields

$$
E\left[w\left(x, t_{k}\right) w\left(x, t_{l}\right)\right]=\int_{-\infty}^{+\infty} \widetilde{\Theta}^{*}\left(\omega, t_{k}\right) \widetilde{\Theta}\left(\omega, t_{l}\right) \mathrm{d} \omega
$$

in which

$$
\begin{aligned}
& \widetilde{\Theta}(x, t, \omega) \\
& \quad=\int_{-\infty}^{+\infty} \int_{-\infty}^{+\infty} \mathbf{G}(x-\zeta, \tau ; 0,0) \tilde{\mathbf{f}}(\zeta, t-\tau, \omega) \mathrm{d} \zeta \mathrm{d} \tau \\
& \widetilde{\mathbf{f}}(\zeta, t, \omega)=\mathbf{A}(\zeta, t) \mathbf{Z}(\omega) \mathbf{s} \sqrt{S_{q q}(\omega)} e^{j \omega t},
\end{aligned}
$$


where (18) is called pseudo excitation and (17) is pseudo response of the structure under the pseudo excitation.

Let $t_{k}=t_{l}=t$ in (13). The autocorrelation function of $w(x, t)$ can be obtained from (17) and (18) as

$$
E[w(x, t) w(x, t)]=\int_{-\infty}^{+\infty} \widetilde{\Theta}^{*}(x, t, \omega) \widetilde{\Theta}(x, t, \omega) \mathrm{d} \omega .
$$

The integrand in (19) is the evolutionary power spectral density of the nonstationary random vibration response of the structure as

$$
S_{w w}(x, t, \omega)=\widetilde{\Theta}^{*}(x, t, \omega) \widetilde{\Theta}(x, t, \omega) .
$$

The results derived in (19)-(20) show that only the pseudo response analysis is needed to estimate the evolutionary power spectrum of the nonstationary random vibration of the structure under moving random loads. This is as the idea of the pseudo excitation method (PEM).

4.2. Nonstationary Random Vibration Analysis under a Moving Random Load. As shown in Section 4.1, the nonstationary random vibration analysis of the system under moving random loads can be directly analyzed by applying a pseudo excitation to the structure. The superposition principle can be adopted because the system is linear. For the excitation on the right side of (1), the response of the structure under each load alone can be computed, and then the total response can be obtained by using the superposition principle.

The pseudo response of a structure under the $i$ th moving pseudo load $\widetilde{q}\left(t-t_{i}\right)$ can be expressed using (17) and (18) as

$$
\begin{aligned}
& \widetilde{\Theta}_{i}(x, t, \omega) \\
& =\int_{-\infty}^{+\infty} \int_{-\infty}^{+\infty} G(x-\zeta, \tau ; 0,0) \delta\left(\zeta-v\left(\left(t-t_{i}\right)-\tau\right)\right) \\
& \quad \cdot \widetilde{q}\left(\left(t-t_{i}\right)-\tau, \omega\right) \mathrm{d} \zeta \mathrm{d} \tau .
\end{aligned}
$$

Then (7) gives

$$
\begin{aligned}
& \widetilde{\Theta}_{i}(x, t, \omega)=\frac{1}{4 \pi^{2}} \\
& \cdot \int_{-\infty}^{+\infty} \int_{-\infty}^{+\infty} \int_{-\infty}^{+\infty} \int_{-\infty}^{+\infty} H\left(k_{x}, k_{t}\right) e^{j k_{t} \tau} e^{j k_{x}(x-\zeta)} \\
& \cdot \delta\left(\zeta-v\left(\left(t-t_{i}\right)-\tau\right)\right) \\
& \cdot \sqrt{S_{q q}(\omega)} e^{j \omega\left(\left(t-t_{i}\right)-\tau\right)} \mathrm{d} k_{x} \mathrm{~d} k_{t} \mathrm{~d} \zeta \mathrm{d} \tau=T_{i}(x, t, \omega) \\
& \cdot \sqrt{S_{q q}(\omega)} e^{j \omega t}
\end{aligned}
$$

in which

$$
\begin{aligned}
& T_{i}(x, t, \omega) \\
& \quad=\frac{1}{2 \pi} e^{-j \omega t_{i}} \int_{-\infty}^{+\infty} H\left(k_{x}, \omega-k_{x} v\right) e^{j k_{x}\left(x-v\left(t-t_{i}\right)\right)} \mathrm{d} k_{x} .
\end{aligned}
$$

Repeating (21)-(23), after the response of the structure under all $n$ moving pseudo loads has been computed, the total response of the structure can be obtained using the superposition principle

$$
\begin{aligned}
\widetilde{\Theta}(x, t, \omega) & =\sum_{i=1}^{n} \widetilde{\Theta}_{i}(x, t, \omega) \\
& =\left(\sum_{i=1}^{n} T_{i}(x, t, \omega)\right) \sqrt{S_{q q}(\omega)} e^{j \omega t} .
\end{aligned}
$$

According to the PEM, (24) multiplied by its complex conjugate and the nonstationary PSD of the vertical displacement of the structure under the moving random loads can be obtained as

$$
\begin{aligned}
& S_{w w}(x, t, \omega)=\widetilde{\Theta}^{*}(x, t, \omega) \cdot \widetilde{\Theta}(x, t, \omega) \\
& \quad=\Gamma(x, t, \omega) S_{q q}(\omega) \\
& \Gamma(x, t, \omega)=\left(\sum_{i=1}^{n} T_{i}(x, t, \omega)\right)^{*}\left(\sum_{i=1}^{n} T_{i}(x, t, \omega)\right) .
\end{aligned}
$$

Here, (25)-(26) are the closed-form solution of the nonstationary random vibration response of the structure under the sequence of moving random loads, which has a clear physical meaning, as it can be understood as an evolutionary modulation process of the power spectrum of excitation. In (26) $T_{i}(x, t, \omega)$ also can be called modulation function.

Further, the time-dependent standard deviation of the displacement is computed as

$$
\sigma_{w}^{2}(x, t)=2 \int_{0}^{\infty} S_{w w}(x, t, \omega) \mathrm{d} \omega .
$$

4.3. Numerical Integration Strategy. The closed-form solution of PSD and the standard deviation of the beam displacement have been derived. But it is shown that the mathematical expression is a generalized integration on an infinite domain, which cannot be used to solve practical engineering problems. To obtain an effective numerical solution, a numerical integration strategy must be devised.

It is assumed that the nonstationary random vibration analysis is carried out at an arbitrary observation point $x=$ $x_{0}$. From Section 4.2 it can be seen that the evolutionary PSD of the nonstationary random vibration at the observation point can be computed using (25) as long as the modulation function $\Gamma\left(x_{0}, t, \omega\right)$ has been calculated. As can be observed in (23), the calculation of $T_{i}\left(x_{0}, t, \omega\right)$ is a one-dimensional integration problem in the wavenumber domain.

Generally Simpson's rule can be considered a suitable numerical integration method. For the responses of the system under moving random loads, the efficiency of Simpson's rule is not high because a large number of frequency points must be computed. Particularly, when analyzing the random vibration excited by a series of loads with time delay using superposition principle the numerical integral efficiency is a very important problem.

From (23) it can be seen that the integrand has a very close relationship with the inverse Fourier transform. Compared with a conventional inverse Fourier analysis, the wavenumber 
multiplier in the exponential term $e^{j k_{x}\left(x_{0}-v\left(t-t_{i}\right)\right)}$ is $\left(x_{0}-v(t-\right.$ $\left.t_{i}\right)$ ) in (23). Using $x_{1}=x_{0}+v t_{i}$, (23) becomes

$$
\begin{aligned}
& T_{i}\left(x_{0}, t, \omega\right)=\frac{1}{2 \pi} \\
& \cdot e^{-j \omega t_{i}} \int_{-\infty}^{+\infty} H\left(k_{x}, \omega-k_{x} v\right) e^{j k_{x}\left(x_{1}-v t\right)} \mathrm{d} k_{x}=\frac{1}{2 \pi v} \\
& \cdot e^{-j \omega t_{i}} \int_{-\infty}^{+\infty} H\left(k_{x}, \omega-k_{x} v\right) e^{j\left(v k_{x}\right)\left(x_{1} / v-t\right)} \mathrm{d}\left(v k_{x}\right) .
\end{aligned}
$$

Let $\bar{k}_{t}=v k_{x}, t_{1}=x_{1} / v$, and $\bar{t}=x_{1} / v-t$. Equation (28) can be rewritten as

$$
\begin{aligned}
& T_{i}\left(x_{0}, t, \omega\right) \\
& \quad=\frac{1}{2 \pi v} e^{-j \omega t_{i}} \int_{-\infty}^{+\infty} \bar{H}\left(\frac{\bar{k}_{t}}{v}, \omega-\bar{k}_{t}\right) e^{j \bar{k}_{t} \bar{t}} \mathrm{~d} \bar{k}_{t}
\end{aligned}
$$

in which $\bar{H}\left(\bar{k}_{t} / v, \omega-\bar{k}_{t}\right)=H\left(k_{x}, \omega-k_{x} v\right)$.

Assuming $\bar{h}(\bar{t})=\int_{-\infty}^{+\infty} \bar{H}\left(\bar{k}_{t} / v, \omega-\bar{k}_{t}\right) e^{j \bar{k}_{t} \bar{t}} \mathrm{~d} \bar{k}_{t}$, (29) can be simplified as follows:

$$
\begin{aligned}
T_{i}\left(x_{0}, t, \omega\right) & =\frac{1}{2 \pi v} e^{-j \omega t_{i}} \bar{h}(\bar{t}) \\
& =\frac{1}{2 \pi v} e^{-j \omega t_{i}} \bar{h}\left(\frac{x_{0}}{v}+t_{i}-t\right) .
\end{aligned}
$$

Here, $\bar{h}(\bar{t})$ and $\bar{H}\left(\bar{k}_{t} / v, \omega-\bar{k}_{t}\right)$ constitute a Fourier transform pair.

In the case of unilateral expansion, if $i>N / 2$, then $\bar{H}_{i}=$ $\bar{H}\left(\bar{k}_{t}=\bar{k}_{t}^{i}\right)$ must be the complex conjugate of $\bar{H}_{N-i}=\bar{H}\left(\bar{k}_{t}=\right.$ $\left.\bar{k}_{t}^{N-i}\right)$. To satisfy the relationship, $\bar{k}_{x}^{i}$ can be assigned by [36, 37]

$$
\begin{aligned}
& \bar{k}_{t}^{i}=i \Delta \bar{k}_{t} \quad \text { for } 0 \leq i \leq \frac{N}{2} \\
& \bar{k}_{t}^{i}=-(N-i) \Delta \bar{k}_{t} \quad \text { for } \frac{N}{2}<i \leq N-1 .
\end{aligned}
$$

The response of the system at time $t=t_{n}$, as $\bar{h}_{n}=\bar{h}(\bar{t}=$ $\left.\bar{t}_{n}\right)$, can be computed by

$$
\bar{h}_{n}=\sum_{i=0}^{N-1} \bar{H}_{i} e^{j \bar{k}_{t}^{i} t_{n}}=\sum_{i=0}^{N-1} \bar{H}_{i} e^{j(2 \pi n i / N)}
$$

Thus, $\bar{h}(\bar{t})$ can be obtained from $\bar{H}\left(\bar{k}_{t}\right)$ by using discrete inverse fast Fourier transform, and ultimately $T_{i}\left(x_{0}, t, \omega\right)$ can be computed. It can be seen that the proposed method has high computational efficiency through the variable substitution and translation.

\subsection{Critical Velocity Analysis}

4.4.1. Moving Constant Load. If the damping of the Kelvin foundation is equal to zero, it is a Winkler foundation, and then the displacement of the beam resting on the Winkler foundation subjected to a moving constant load $P$ can be expressed as

$$
w(x, t)=\frac{P}{2 \pi} \int_{-\infty}^{\infty} \frac{e^{j k_{x}(x-v t)}}{E I k_{x}^{4}+K-\bar{m} k_{x}^{2} v^{2}} \mathrm{~d} k_{x} .
$$

Suppose

$$
E I k_{x}^{4}+K-\bar{m} k_{x}^{2} v^{2}=0
$$

and the positive solution for $v$ of (34) is given as

$$
v_{\sin }=\sqrt{\frac{E I}{\bar{m}} k_{x}^{2}+\frac{K}{\bar{m} k_{x}^{2}}} .
$$

According to the extreme value theory, $v_{\text {sin }}\left(k_{x}\right)$ has the minimum value $v_{c}$ as

$$
v_{\sin } \geq v_{c}=\left(\frac{4 K E I}{\bar{m}^{2}}\right)^{1 / 4}
$$

which is the (conventional) critical velocity of the infinite beam resting on a Winkler foundation subjected to a moving constant load. Only when $v \geq v_{c}$ does the integrand in (33) have a singularity. Equation (36) indicates that the critical velocity is determined by the Winkler foundation stiffness and the bending stiffness and mass per unit length of the beam.

4.4.2. Moving Harmonic Load. If the load is a harmonic one in the form of $P e^{j \omega t}$, for undamped system (i.e., $\eta=0$ ), the displacement of the infinite beam can be expressed as

$$
w(x, t)=\frac{P e^{j \omega t}}{2 \pi} \int_{-\infty}^{\infty} \frac{e^{j k_{x}(x-v t)}}{E I k_{x}^{4}+K-\bar{m}\left(\omega-k_{x} v\right)^{2}} \mathrm{~d} k_{x} .
$$

The discussion of the critical velocity is similar to (33) and the response has a singularity because the denominator of integrand can be equal to zero. But it must be noticed that the singularity of the integrand simultaneously involves velocity $v$ and frequency $\omega$, as

$$
E I k_{x}^{4}+K-\bar{m}\left(\omega-k_{x} v\right)^{2}=0 .
$$

The positive solution of (38) is given as

$$
v=\frac{\omega}{k_{x}}+\sqrt{\frac{E I k_{x}^{2}}{\bar{m}}+\frac{K}{\bar{m} k_{x}^{2}}} .
$$

From the above expressions it can be observed that the critical velocity of the system under a moving harmonic load is not a system parameter but rather is related to the frequency of excitation $\omega$. So the critical velocity is only discussed under a given frequency $\omega$.

4.4.3. Moving Random Load. From Section 4.1 it can be seen that the power spectral response analysis of the nonstationary random vibration of an infinite beam subjected to moving 
random loads can be converted into the particular deterministic vibration subjected to a moving harmonic load. For the power spectral analysis each frequency point must be evaluated within the frequency bandwidth.

For an undamped system $(\eta=0)$, a similar discussion on the critical velocity to that in Section 4.4.2 can be made. However, a critical velocity in this case cannot be defined like the cases under a moving constant load or a moving harmonic load because all frequencies in the bandwidth are needed to analyze the random vibration problem.

For a damped system $(\eta \neq 0)$, (23) becomes

$$
\begin{aligned}
& T_{i}(x, t, \omega)=\frac{1}{2 \pi} \\
& \quad \cdot e^{-j \omega t_{i}} \int_{-\infty}^{\infty} \frac{e^{j k_{x}\left(x-v\left(t-t_{i}\right)\right)}}{E I k_{x}^{4}+K+i \eta\left(\omega-k_{x} v\right)-\bar{m}\left(\omega-k_{x} v\right)^{2}} \mathrm{~d} k_{x} .
\end{aligned}
$$

The denominator being zero means

$$
\begin{aligned}
E I k_{x}^{4}+K-\bar{m}\left(\omega-k_{x} v\right)^{2} & =0 . \\
j \eta\left(\omega-k_{x} v\right) & =0
\end{aligned}
$$

Obviously (41) has no solution for $v$, which implies that (40) does not have a singularity, but (40) has a maximum, which is determined by velocity $v$ and frequency $\omega$.

\section{Numerical Examples}

The parameters of the system shown in [38] are given in Table 1 , which are used to analyze nonstationary random vibration of the infinite beam resting on the Kelvin foundation. The band-limited white noise is taken to represent the PSD of the moving random load:

$$
S_{f}(\omega)=10^{8} \mathrm{~N}^{2} /\left(\mathrm{rad} \cdot \mathrm{s}^{-1}\right), \quad \omega \in[0.1 \pi, 100 \pi] .
$$

5.1. Validation of the Proposed Method. In Section 4.3, it has been pointed out that to analyze the nonstationary random vibration of a structure under a moving random load the integration of (23) needs to be computed by using FEM-FT method and this can be carried out by discrete inverse fast Fourier transform (DIFFT) through a variable substitution and translation. The results obtained by Simpson's rule are used to compare with DIFFT results to demonstrate the effectiveness and accuracy of the proposed method. Meanwhile, in order to verify the correctness of the results by the proposed method a Monte Carlo simulation based on the random sample analysis is also used to compute the statistical values of the structural response.

For Monte Carlo method the moving random load samples are generated by

$$
f(t)=\sqrt{2} \sum_{k=1}^{N} \sqrt{S_{q q}\left(\omega_{k}\right) \Delta \omega} \cos \left(\omega_{k} t+\theta_{k}\right),
$$

where $S_{q q}\left(\omega_{k}\right)$ is the value of $S_{q q}(\omega)$ at the $k$ th frequency $\omega_{k}$ and $\Delta \omega$ is a small regular discretization interval, $\theta_{k}$ is the
TABLE 1: Parameters of the system.

\begin{tabular}{lcccc}
\hline$E I\left(\mathrm{~N} \cdot \mathrm{m}^{2}\right)$ & $\bar{m}\left(\mathrm{~kg} \cdot \mathrm{m}^{-1}\right)$ & $K(\mathrm{MPa})$ & $\eta\left(\mathrm{kNs} \cdot \mathrm{m}^{-2}\right)$ & $v_{c}\left(\mathrm{~m} \cdot \mathrm{s}^{-1}\right)$ \\
\hline $2.3 \times 10^{3}$ & 48.2 & 68.9 & 34.6 & 128.5 \\
\hline
\end{tabular}

corresponding phase of $\omega_{k}$ and is taken as a random variable uniformly distributing over the range $[0,2 \pi] .500$ samples of $\theta_{k}$ are taken to compute the standard deviation.

Two cases, as (a) $v=40 \mathrm{~m} \mathrm{~s}^{-1}$ and (b) $v=75 \mathrm{~m} \mathrm{~s}^{-1}$, are considered, respectively. The nonstationary time-dependent standard deviation of the vertical displacement at the origin is shown in Figures 2(a) and 2(b). As can be observed in these figures the numerical results from the DIFFT, Complex Simpson's rule, and Monte Carlo method agree well. In both cases, the computational time of DIFFT is $2.3 \mathrm{~s}$, the computational time of Simpson's rule is $394.9 \mathrm{~s}$, and the computational time of Monte Carlo method is $877 \mathrm{~s}$ (500 samples). Obviously the proposed method has a superior computational advantage over the other two methods. Moreover, from Figures 2(a) and 2(b) it also can be seen that the proposed random vibration method has good agreement with Monte Carlo simulations.

5.2. Influence of Velocity. For the case of an undamped system $(\eta=0)$ the critical velocity under a deterministic moving pseudo harmonic load is discussed firstly. Assuming frequency $\omega \in[0,300] \mathrm{rad} \mathrm{s}^{-1},(38)$ is taken to analyze the critical velocity by the numerical experiment and the results are listed in Table 2. It can be seen that the critical velocity is $128.5 \mathrm{~m} \mathrm{~s}^{-1}$ when $\omega=0$ as the case of moving constant load. The critical velocity is $104.6 \mathrm{~m} \mathrm{~s}^{-1}$ when $\omega=300 \mathrm{rad} \mathrm{s}^{-1}$. From Table 2 it also can be seen that the critical velocity decreases with the increase of the frequency.

For the case of damped system $(\eta \neq 0)$, the velocity is increased from 0 to $300 \mathrm{~m} \mathrm{~s}^{-1}$ at a constant step of $2 \mathrm{~m} \mathrm{~s}^{-1}$ in the simulation. The time-dependent standard deviation of vertical displacement at the origin at different load velocities and its maximums are given in Figures 3(a) and 3(b), respectively. Results show that the critical velocity is $v_{r}=$ $120 \mathrm{~m} \mathrm{~s}^{-1}$, which is defined as the velocity corresponding to the overall maximum of the standard deviation. This critical velocity is slightly lower than $v_{c}=128.5 \mathrm{~m} \mathrm{~s}^{-1}$, which is the critical velocity of the system under a moving constant load. When the moving velocity of load is smaller than $v_{r}$, the standard deviation increases as the load velocity increases. When the load velocity is close to $v_{r}$, the response achieves its maximum, and then the response decreases with increasing velocity. The main reason is that the vibration frequency of response becomes higher while the load is close to the origin but the vibration frequency of response becomes lower while the load moves away from the origin because of the Doppler effect. The damping of the system can cause faster attenuation of the response of the high frequency vibration, but the response of the low frequency vibration can remain for a relatively long period of time. Also, due to the influence of the foundation damping, the response has not reached its maximum when the load reaches the origin, but instead the response achieves its maximum when the load has passed the 


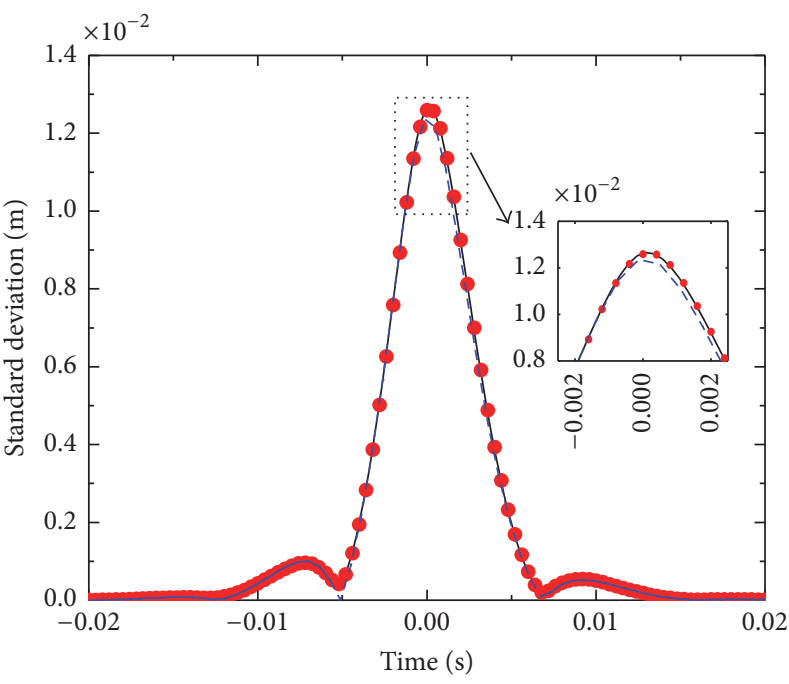

(a) $v=40 \mathrm{~m} \mathrm{~s}^{-1}$

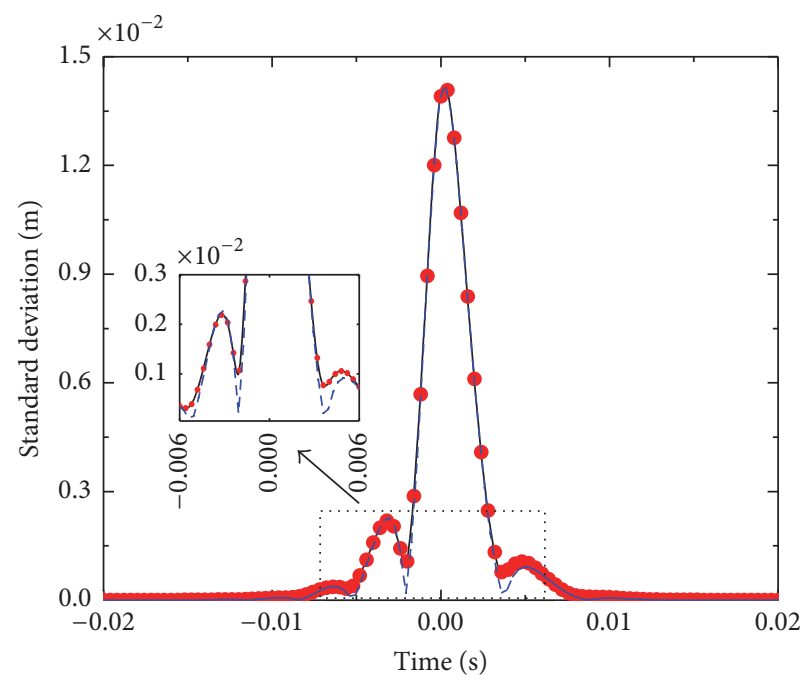

(b) $v=75 \mathrm{~m} \mathrm{~s}^{-1}$

FIGURE 2: Time-dependent standard deviation of vertical displacement at the origin (black solid line: DIFFT; red dots: Simpson's rule; blue dashed line: Monte Carlo method).

TABLE 2: Critical velocity of system under a moving pseudo harmonic load with different frequency.

\begin{tabular}{lc}
\hline Frequency $\left(\mathrm{rad} \mathrm{s}^{-1}\right)$ & Critical velocity $\left(\mathrm{m} \mathrm{s}^{-1}\right)$ \\
\hline 0 & 128.5 \\
50 & 124.7 \\
100 & 120.7 \\
150 & 116.9 \\
200 & 112.8 \\
250 & 108.7 \\
300 & 104.6 \\
\hline
\end{tabular}

origin a moment later-the phenomenon is called time lag. In fact, when the damping is zero, the response achieves its maximum when the load has reached the origin. Meanwhile, the vibration frequency of response is the same before and after the load passes the origin.

5.3. Influence of Damping. In Section 5.2, the critical velocity $v_{r}$ under the moving random load is found to be slightly lower than conventional critical velocity $v_{c}$, which is an interesting phenomenon. In this section the mechanism of the critical velocity is studied, in which the bending stiffness of the beam and the mass per unit length remain unchanged, so that the effect of stiffness and damping of foundation on the critical velocity is the focus of study here.

For the convenience of discussion, the critical damping and damping ratio are defined as

$$
\begin{aligned}
\eta_{c r} & =2 \sqrt{\bar{m} K}, \\
\xi & =\frac{\eta}{\eta_{c}} .
\end{aligned}
$$

Figure 4 shows results of the maximum of the timedependent standard deviation at different velocities for six damping ratios. It can be seen that smaller damping leads to larger standard deviation at the same speed. When damping ratio is $\xi=0.05$, the maximum of the standard deviation appears at $v_{r}=130 \mathrm{~m} \mathrm{~s}^{-1}$, which is very close to critical velocity $v_{c}=128.5 \mathrm{~m} \mathrm{~s}^{-1}$ under a moving constant load. In addition, the critical velocity under a moving random load is not constant, which becomes gradually smaller as the damping increases and lower than the critical velocity under a moving constant load. In the case of a relatively small damping ( $\xi \leq 0.5)$, the system's response has an obvious peak. The maximum of the standard deviation increases with increasing velocity below critical velocity $v_{r}$. The response reaches a maximum when the velocity reaches a critical velocity and then decreases gradually. In the case of a relatively large damping ( $\xi \geq 0.8$ ), the critical velocity of the system does not exist and the response decreases with increasing velocity from the beginning. It can be seen that the main effect of the damping is to reduce the magnitude of the response and the critical velocity of the system.

Figure 5 shows the moment corresponding to the maximum of time-dependent standard deviation, as time delay of the response reaches its maximum, and after the random load has passed the origin. These curves intersect near critical velocity $v_{r}$, which is a very interesting phenomenon. It can be observed that the time delay increases with increasing velocity. Before reaching critical velocity $v_{r}$, the greater the damping, the greater the time delay. But, above critical velocity $v_{r}$, the greater the damping, the smaller the time delay. This shows that the effect of the damping is different below and above critical velocity $v_{r}$, indicating that the damping changes the time delay. 


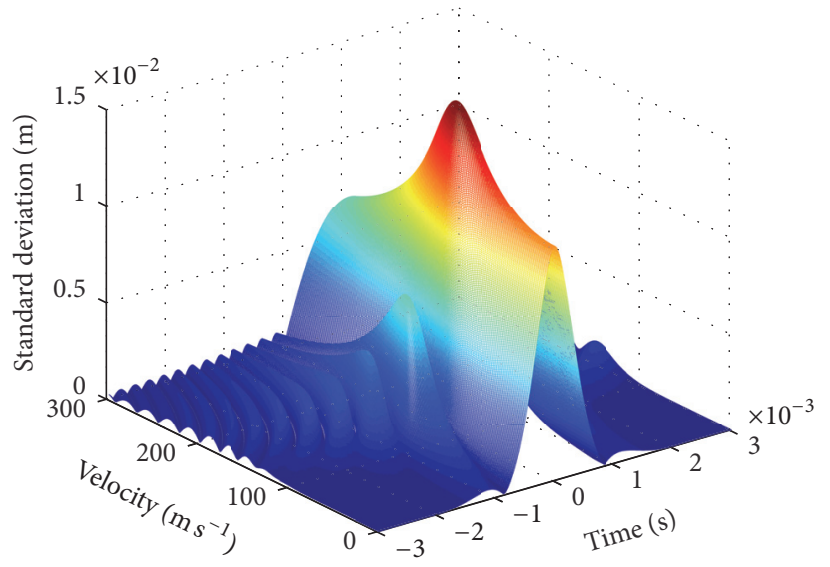

(a) Time-dependent standard deviation

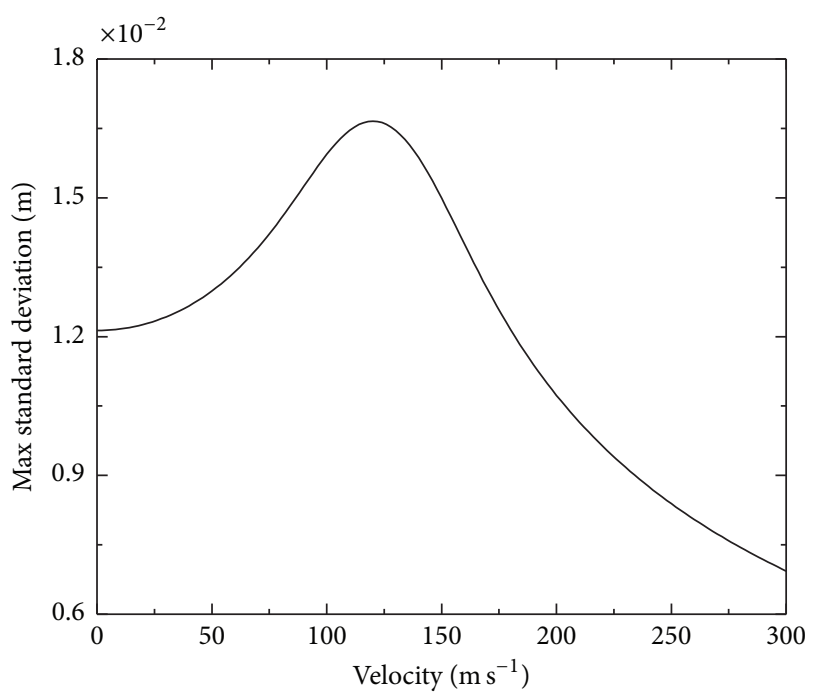

(b) Maximum at different velocities

FIGURE 3: Nonstationary random vibration response at different velocities.

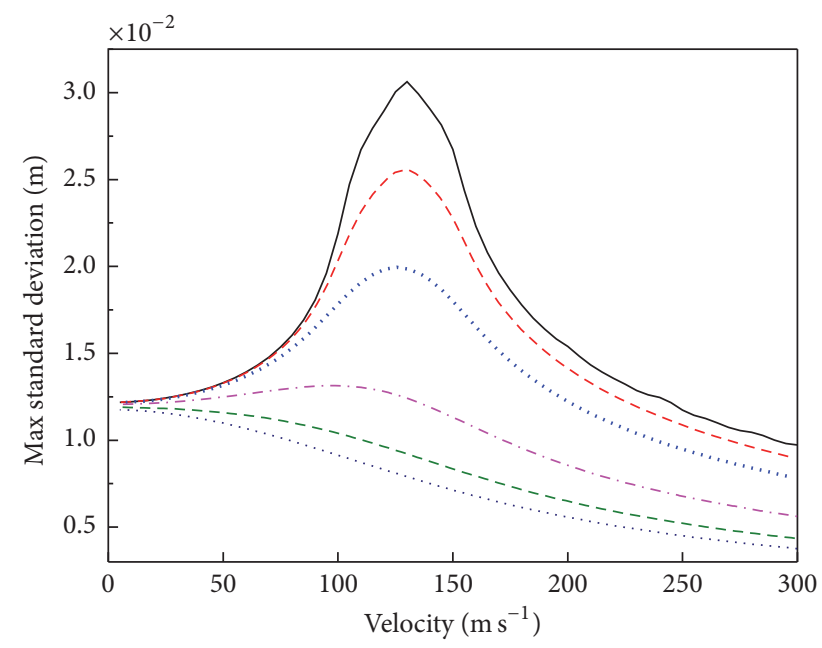

FIGURE 4: Maximum of time-dependent standard deviation at different velocities (black solid line: $\xi=0.05$; red dashed line: $\xi=$ 0.1 ; blue thick-dotted line: $\xi=0.2$; pink dash-dotted line: $\xi=0.5$; green dashed line: $\xi=0.8$; blue thin-dotted line: $\xi=1$ ).

5.4. Influence of Foundation Stiffness. In this section, the effect of the foundation stiffness on the critical velocity is mainly investigated. Six values of foundation stiffness $K$ are adopted and the critical velocities corresponding to stiffness values are listed in Table 3. The damping ratio of the foundation is taken as $\xi=0.5$.

Figure 6 shows the maximum of time-dependent standard deviation of the response at different velocities. At the same velocity, the standard deviation is larger when the foundation stiffness is smaller. When the foundation stiffness is lower than $40 \mathrm{MPa}$, the standard deviation decreases with the increasing load velocity. The reason is that a critical

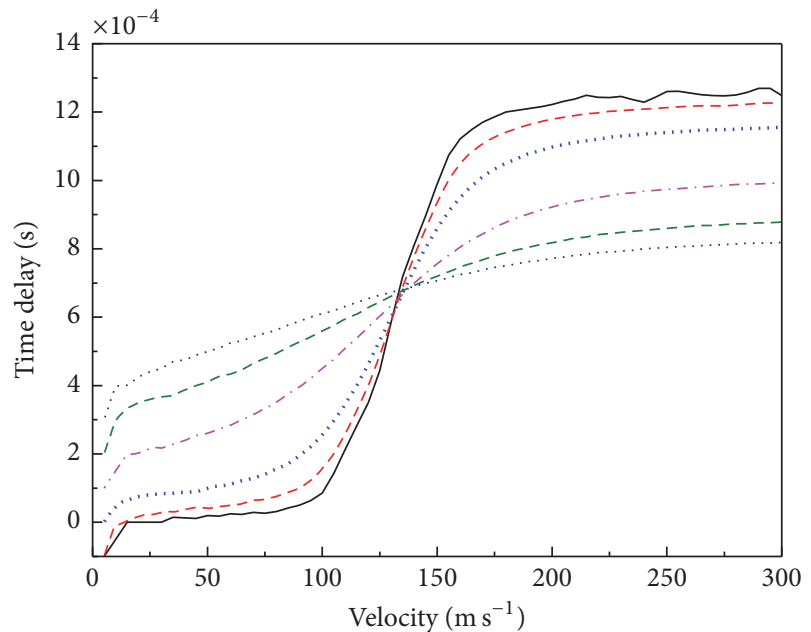

FIGURE 5: Time delay corresponding to maximum of timedependent standard deviation at different velocities (black solid line: $\xi=0.05$; red dashed line: $\xi=0.1$; blue thick-dotted line: $\xi=0.2$; pink dash-dotted line: $\xi=0.5$; green dashed line: $\xi=0.8$; blue thindotted line: $\xi=1$ ).

TABLE 3: Different foundation stiffness and corresponding critical velocities of the system.

\begin{tabular}{lc}
\hline Foundation stiffness $(\mathrm{MPa})$ & Critical velocity $\left(\mathrm{m} \mathrm{s}^{-1}\right)$ \\
\hline 30 & 104.4 \\
40 & 112.2 \\
50 & 118.6 \\
60 & 124.2 \\
80 & 133.4 \\
100 & 141.1 \\
\hline
\end{tabular}




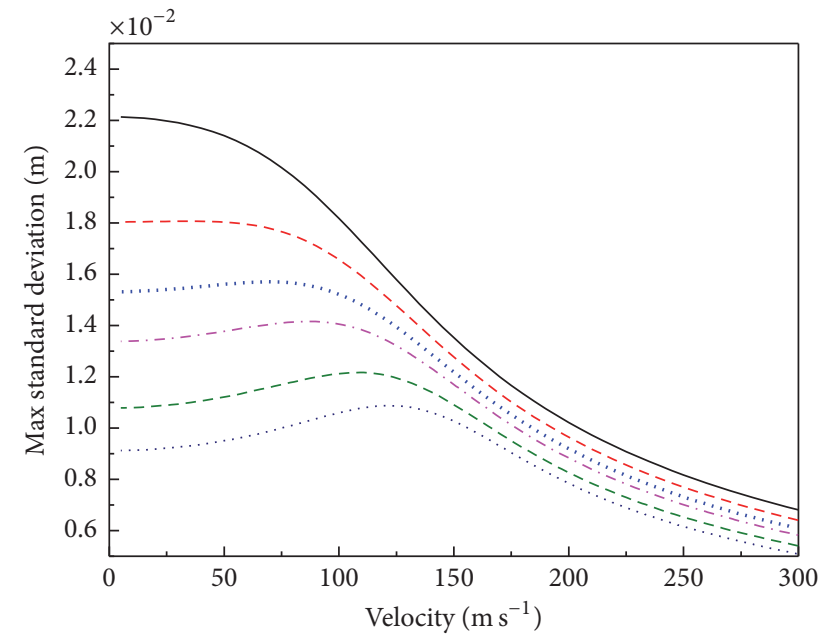

FIGURE 6: Maximum of time-dependent standard deviation at different velocity (black solid line: $K=30 \mathrm{MPa}$; red dashed line: $K=40 \mathrm{MPa}$; blue thick-dotted line: $K=50 \mathrm{MPa}$; pink dash-dotted line: $K=60 \mathrm{MPa}$; green dashed line: $K=80 \mathrm{MPa}$; blue thin-dotted line: $K=100 \mathrm{MPa}$ ).

velocity cannot be well defined as the damping reduces the response significantly when foundation stiffness is small. A peak in the response of the system is not distinct when the foundation stiffness reaches a certain level such as $K=$ $60 \mathrm{MPa}$. However, the critical velocity in these cases is significantly lower than the critical velocity under a moving constant load. The critical velocity under a moving random load is close to the critical velocity under a moving constant load when the stiffness of foundation is greater than $100 \mathrm{MPa}$. Relatively to the larger stiffness of the foundation the damping effect weakens. The critical velocity of the system depends on the relationship between the stiffness and damping of the foundation. If the damping of the foundation is small relative to its stiffness, the system has a more obvious critical velocity, and it is close to the critical velocity under a moving constant load. But when the damping of the foundation is large relative to the stiffness of foundation, the critical velocity of the system is not apparent.

Figure 7 shows the time delay of the response reaching its maximum. From Figure 7 it can be seen that the time delay increases with increasing velocity at any stiffness value of the foundation. The increase in the time delay levels off at high stiffness values of the foundation. In contrast with Figure 5 it can be seen that the rate of the time delay is related to damping mainly, while the stiffness of the foundation just changes the magnitude, but not the rate, of the time delay.

5.5. Influence of Coherence of Load. Figure 8 shows the timedependent standard deviation when fully coherent random loads are considered. Meanwhile, the results of the uniform excitation also are shown in Figure 8 in order to compare the effects of load coherence. In the following analysis the spacing between adjacent moving loads is $0.5 \mathrm{~m}$. When load

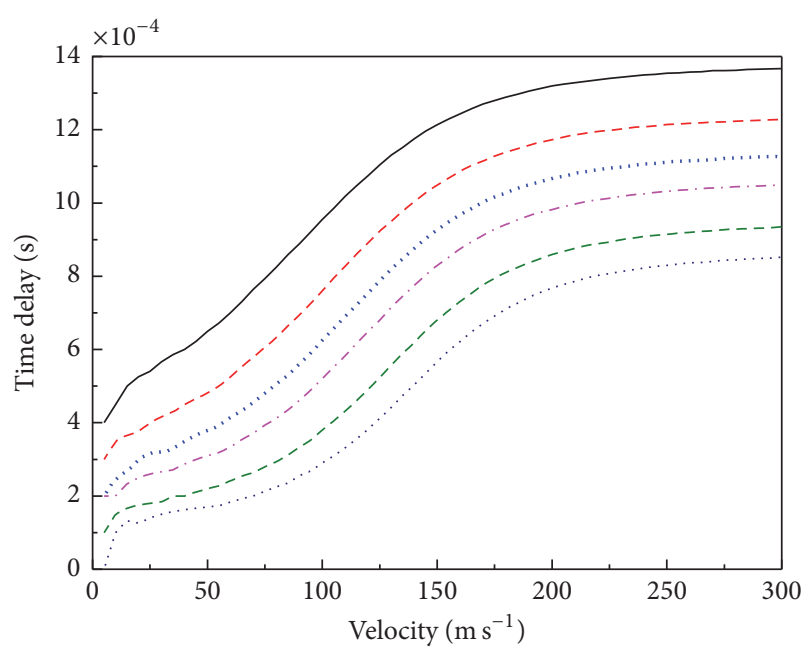

FIgURE 7: Time delay corresponding to maximum of timedependent standard deviation at different velocity (black solid line: $K=30 \mathrm{MPa}$; red dashed line: $K=40 \mathrm{MPa}$; blue thick-dotted line: $K=50 \mathrm{MPa}$; pink dash-dotted line: $K=60 \mathrm{MPa}$; green dashed line: $K=80 \mathrm{MPa}$; blue thin-dotted line: $K=100 \mathrm{MPa}$ ).

velocity is $40 \mathrm{~m} \mathrm{~s}^{-1}$, the effect of fully coherent loads on the results is very small. The reason is that the duration of the peak response of the structure under a single load $(t \in$ $[-0.005,0.005] \mathrm{s})$ is shorter than the time lag, reflecting the load coherence between adjacent loads $(\Delta t=0.5 / 40=$ $0.0125 \mathrm{~s}$ ), so that the coherence is not significant. Figure 8(a) shows that the response coherence induced by adjacent loads is not strong, and there are four independent peaks. However, as the velocity increases the duration of the individual response induced by a single load is longer than the time lag between the adjacent loads (e.g., $\Delta t=0.5 / 160=0.003125 \mathrm{~s}$ ). The results, such as those in Figures $8(\mathrm{~b})-8(\mathrm{~d})$, show that the responses have strong coherence due to the closeness of the adjacent loads. The responses induced by the fully coherent loads are influenced by the harmonic components (i.e., in $\mathbf{Z}(\omega)$ in (14)), so that they are always smaller than the responses induced by all four loads that are applied at the same time without time lag as a special case. With increasing load velocity the phenomenon will become increasingly significant. It can be seen that when the structure is subjected to a series of moving random loads, load coherence must be considered if the moving load velocity is high enough.

\section{Conclusions}

In this paper, the closed-form solution of the power spectral responses of the nonstationary random vibration of an infinite beam resting on Kelvin foundation under a sequence of moving random loads is derived by PEM combined with FT. It represents railway track subjected to a travelling train. The dynamic response results obtained by the proposed method are verified using Monte Carlo method. Parametric analysis of the standard deviation of random vibration is carried out, the critical velocity of a system under the moving random 


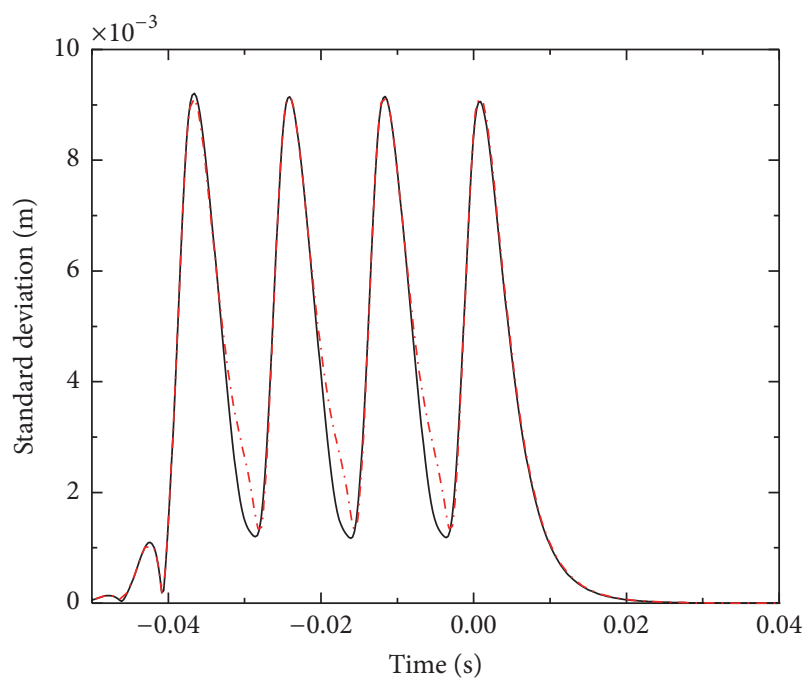

(a) $v=40 \mathrm{~m} \mathrm{~s}^{-1}$

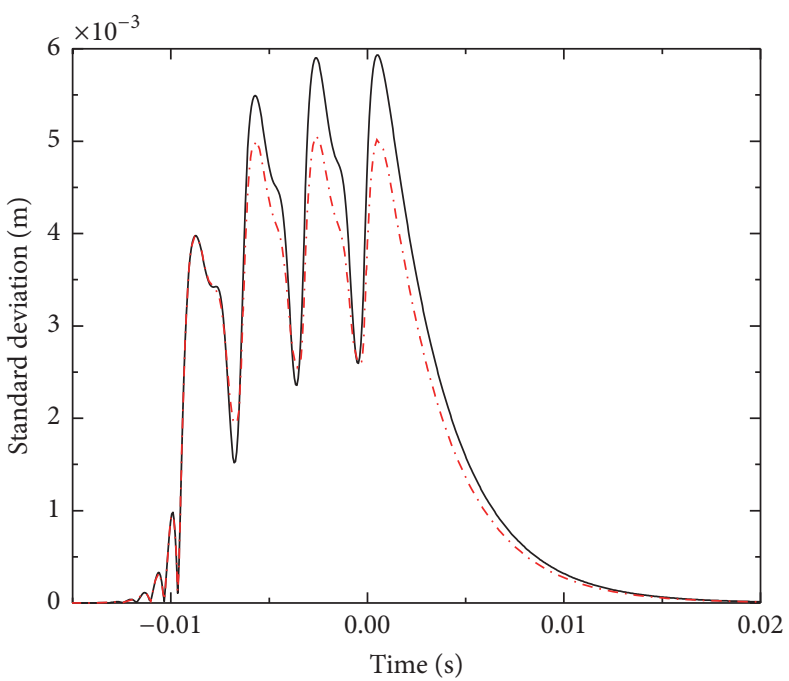

(c) $v=160 \mathrm{~m} \mathrm{~s}^{-1}$

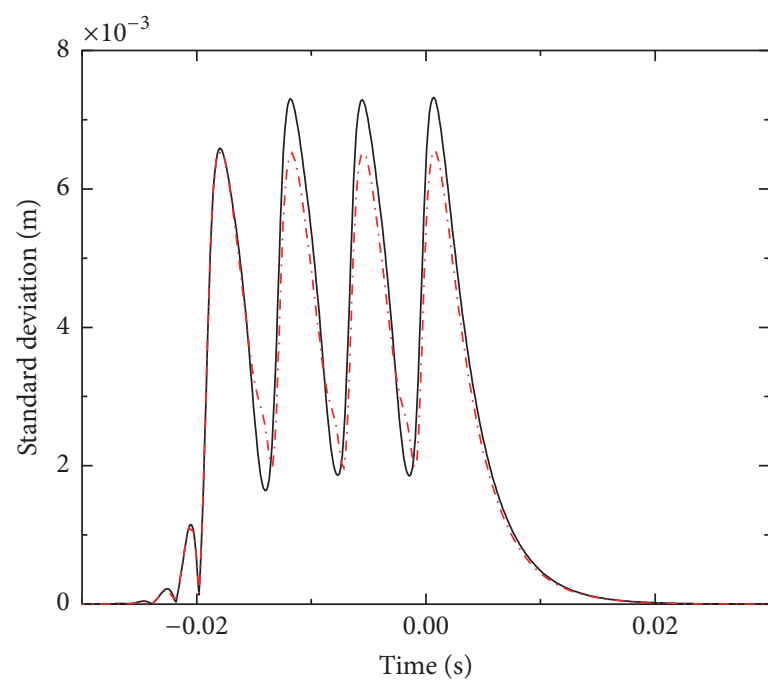

(b) $v=80 \mathrm{~m} \mathrm{~s}^{-1}$

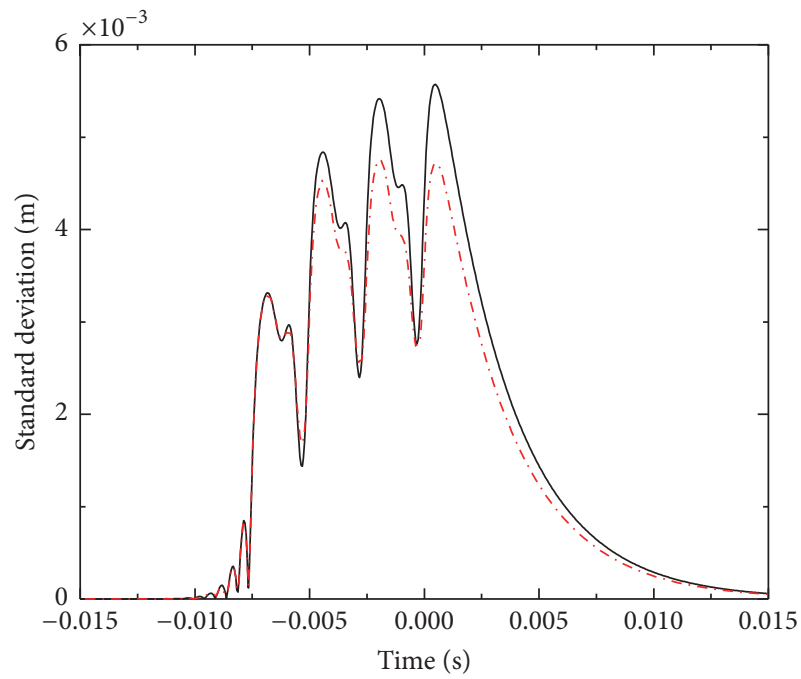

(d) $v=200 \mathrm{~m} \mathrm{~s}^{-1}$

FIGURE 8: Effect of the full coherent loads at different velocities (black solid line: uniform loads; red dashed line: fully coherent loads).

loads is analyzed, and further the mechanism of the critical velocity is discussed. The main conclusions are as follows:

(1) The vibration frequency of the dynamic response of the beam becomes higher when the load is closed to the origin (the observation point) due to Doppler's effect and the duration of the peak response becomes shorter owing to damping. When the load moves away from the origin, the vibration frequency of response becomes lower, and attenuation duration becomes longer.

(2) There is a critical velocity for the system under moving random load. When the load velocity is lower than this critical velocity, the maximum of standard deviation increases with increasing velocity; at the critical velocity, the response achieves the maximum and then decreases gradually afterwards.
(3) For the same stiffness of the foundation the time delay curves versus velocity of the system under different damping intersect near the critical velocity. The effect of damping on the time delay is very different before and after critical velocity.

(4) The critical velocity depends on the relation between damping and stiffness of the foundation. It is well defined only when the damping of foundation relatives to the stiffness of foundation is small enough.

(5) The rate of change of the time delay is mainly related to the damping of the foundation. The stiffness of the foundation just changes the length of the time delay, but not the rate of change of the time delay.

(6) When fully coherent loads are considered the response is always lower than that under the uniform excitation. When the moving load velocity is high 
enough, the impact of the load coherence must be considered.

\section{Additional Points}

Much of this work is carried out during the first author's visit to the University of Liverpool.

\section{Conflicts of Interest}

The authors declare that they have no conflicts of interest.

\section{Acknowledgments}

The authors are grateful for support under grants from the National Basic Research Program of China (2015CB057804) and the Dalian University of Technology Start-Up Fund (DUT16RC(3)027).

\section{References}

[1] L. Frýba, Vibration of Solids and Structures Under Moving Loads, Telford, London, UK, 1999.

[2] Y. B. Yang, J. D. Yau, and Y. S. Wu, Vehicle-Bridge Interaction Dynamics-With Applications to High-Speed Railways, World Scientific, Singapore, 2004.

[3] M. Majka and M. Hartnett, "Dynamic response of bridges to moving trains: a study on effects of random track irregularities and bridge skewness," Computers and Structures, vol. 87, no. 1920, pp. 1233-1252, 2009.

[4] N. D. Beskou and D. D. Theodorakopoulos, "Dynamic effects of moving loads on road pavements: a review," Soil Dynamics and Earthquake Engineering, vol. 31, no. 4, pp. 547-567, 2011.

[5] C. I. Bajer and B. Dyniewicz, Numerical Analysis of Vibrations of Structures under Moving Inertial Load, Springer Science \& Business Media, Berlin, Germany, 2012.

[6] H. Ouyang, "Moving-load dynamic problems: a tutorial (with a brief overview)," Mechanical Systems and Signal Processing, vol. 25, no. 6, pp. 2039-2060, 2011.

[7] A. Der Kiureghian and J. Crempien, "An evolutionary model for earthquake ground motion," Structural Safety, vol. 6, no. 2, pp. 235-246, 1989.

[8] J. P. Conte and B.-F. Peng, "An explicit closed-form solution for linear systems subjected to nonstationary random excitation," Probabilistic Engineering Mechanics, vol. 11, no. 1, pp. 37-50, 1996.

[9] J. D. Achenbach and C. T. Sun, "Moving load on a flexibly supported Timoshenko beam," International Journal of Solids and Structures, vol. 1, no. 4, pp. 353-370, 1965.

[10] C. J. C. Jones, X. Sheng, and M. Petyt, "Simulations of ground vibration from a moving harmonic load on a railway track," Journal of Sound and Vibration, vol. 231, no. 3, pp. 739-751, 2000.

[11] Y.-H. Lin and M. W. Trethewey, "Finite element analysis of elastic beams subjected to moving dynamic loads," Journal of Sound and Vibration, vol. 136, no. 2, pp. 323-342, 1990.

[12] Y.-H. Chen, Y.-H. Huang, and C.-T. Shih, "Response of an infinite tomoshenko beam on a viscoelastic foundation to a harmonic moving load," Journal of Sound and Vibration, vol. 241, no. 5, pp. 809-824, 2001.
[13] H. A. Dieterman and A. Metrikine, "The Equivalent stiffness of a half-space interacting with a beam. Critical velocities of a moving load along the beam," European Journal of Mechanics-A/Solids, vol. 15, no. 1, pp. 67-90, 1996.

[14] H. A. Dieterman and A. V. Metrikine, "Steady-state displacements of a beam on an elastic half-space due to a uniformly moving constant load," European Journal of Mechanics, A/Solids, vol. 16, no. 2, pp. 295-306, 1997.

[15] A. S. J. Suiker, R. De Borst, and C. Esveld, "Critical behaviour of a Timoshenko beam-half plane system under a moving load," Archive of Applied Mechanics, vol. 68, no. 3-4, pp. 158-168, 1998.

[16] T. Yoshimura, J. Hino, and N. Anantharayana, "Vibration analysis of a non-linear beam subjected to moving loads by using the galerkin method," Journal of Sound and Vibration, vol. 104, no. 2, pp. 179-186, 1986.

[17] J. Hino, T. Yoshimura, and N. Ananthanarayana, "Vibration analysis of non-linear beams subjected to a moving load using the finite element method," Journal of Sound and Vibration, vol. 100, no. 4, pp. 477-491, 1985.

[18] M. Şimşek, "Non-linear vibration analysis of a functionally graded Timoshenko beam under action of a moving harmonic load," Composite Structures, vol. 92, no. 10, pp. 2532-2546, 2010.

[19] P. Castro Jorge, F. M. F. Simões, and A. Pinto Da Costa, "Dynamics of beams on non-uniform nonlinear foundations subjected to moving loads," Computers and Structures, vol. 148, pp. 26-34, 2015.

[20] D. Bryja and P. Śniady, "Random vibration of a suspension bridge due to highway traffic," Journal of Sound and Vibration, vol. 125, no. 2, pp. 379-387, 1988.

[21] P. Śniady, "Vibration of a beam due to a random stream of moving forces with random velocity," Journal of Sound and Vibration, vol. 97, no. 1, pp. 23-33, 1984.

[22] P. K. Chatterjee, T. K. Datta, and C. S. Surana, "Vibration of suspension bridges under vehicular movement," Journal of Structural Engineering, vol. 120, no. 3, pp. 681-703, 1994.

[23] H. S. Zibdeh, "Stochastic vibration of an elastic beam due to random moving loads and deterministic axial forces," Engineering Structures, vol. 17, no. 7, pp. 530-535, 1995.

[24] D. Huang and T.-L. Wang, "Vibration of highway steel bridges with longitudinal grades," Computers \& Structures, vol. 69, no. 2, pp. 235-245, 1998.

[25] G. Lombaert, G. Degrande, and D. Clouteau, "Numerical modelling of free field traffic-induced vibrations," Soil Dynamics and Earthquake Engineering, vol. 19, no. 7, pp. 473-488, 2000.

[26] C. W. Kim, M. Kawatani, and K. B. Kim, “Three-dimensional dynamic analysis for bridge-vehicle interaction with roadway roughness," Computers and Structures, vol. 83, no. 19-20, pp. 1627-1645, 2005.

[27] T.-P. Chang and Y.-N. Liu, "Dynamic finite element analysis of a nonlinear beam subjected to a moving load," International Journal of Solids and Structures, vol. 33, no. 12, pp. 1673-1688, 1996.

[28] G. Stefanou, "The stochastic finite element method: past, present and future," Computer Methods in Applied Mechanics and Engineering, vol. 198, no. 9-12, pp. 1031-1051, 2009.

[29] G. Muscolino and T. Alderucci, "Closed-form solutions for the evolutionary frequency response function of linear systems subjected to separable or non-separable non-stationary stochastic excitations," Probabilistic Engineering Mechanics, vol. 40, pp. 7589, 2015. 
[30] R. F. Harrison and J. K. Hammond, "Evolutionary (frequency/time) spectral analysis of the response of vehicles moving on rough ground by using 'covariance equivalent' modelling," Journal of Sound and Vibration, vol. 107, no. 1, pp. 29-38, 1986.

[31] F. Lu, D. Kennedy, F. W. Williams, and J. H. Lin, "Non-stationary random vibration of FE structures subjected to moving loads," Shock and Vibration, vol. 16, no. 3, pp. 291-305, 2009.

[32] J. H. Lin, Y. Zhao, and Y. H. Zhang, "Accurate and highly efficient algorithms for structural stationary/non-stationary random responses," Computer Methods in Applied Mechanics and Engineering, vol. 191, no. 1-2, pp. 103-111, 2001.

[33] J. H. Lin, Y. H. Zhang, and Y. Zhao, "Seismic random response analysis," in Bridge Engineering Handbook, pp. 133-162, 2014.

[34] W. S. Zhang and Y. L. Xu, "Dynamic characteristics and seismic response of adjacent buildings linked by discrete dampers," Earthquake Engineering and Structural Dynamics, vol. 28, no. 10, pp. 1163-1185, 1999.

[35] T. Bierer and C. Bode, "A semi-analytical model in time domain for moving loads," Soil Dynamics and Earthquake Engineering, vol. 27, no. 12, pp. 1073-1081, 2007.

[36] U. Lee, S. Kim, and J. Cho, "Dynamic analysis of the linear discrete dynamic systems subjected to the initial conditions by using an FFT-based spectral analysis method," Journal of Sound and Vibration, vol. 288, no. 1-2, pp. 293-306, 2005.

[37] A. S. Veletsos and C. E. Ventura, "Dynamic analysis of structures by the DFT method," Journal of Structural Engineering, vol. 111, no. 12, pp. 2625-2642, 1985.

[38] L. Sun, "A closed-form solution of beam on viscoelastic subgrade subjected to moving loads," Computers and Structures, vol. 80, no. 1, pp. 1-8, 2002. 


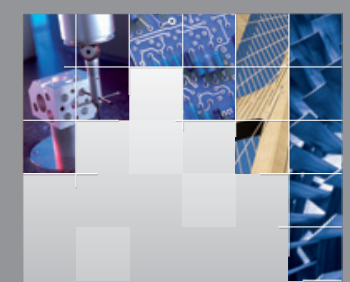

\section{Enfincering}
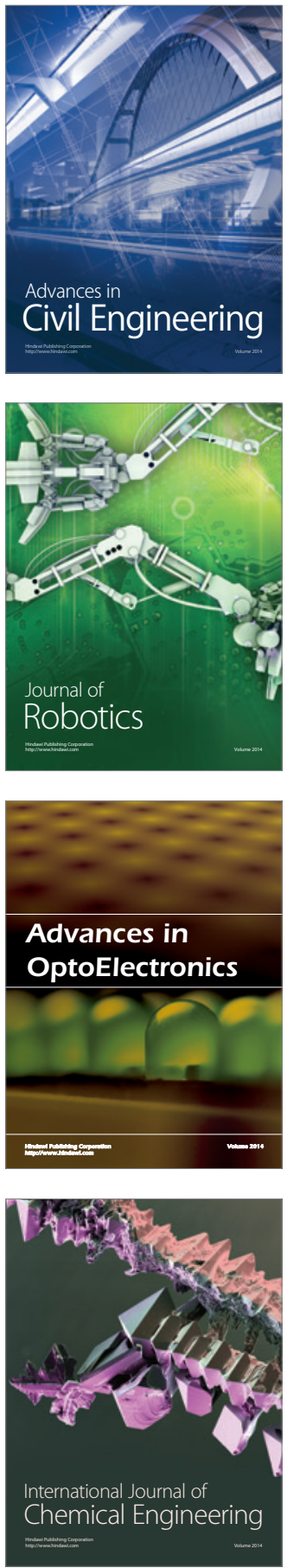

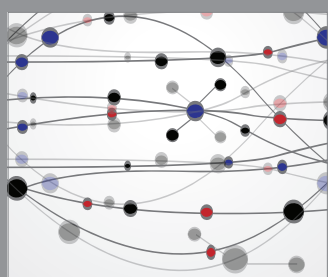

The Scientific World Journal

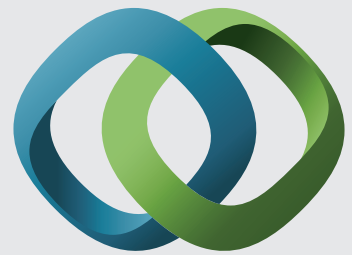

\section{Hindawi}

Submit your manuscripts at

https://www.hindawi.com
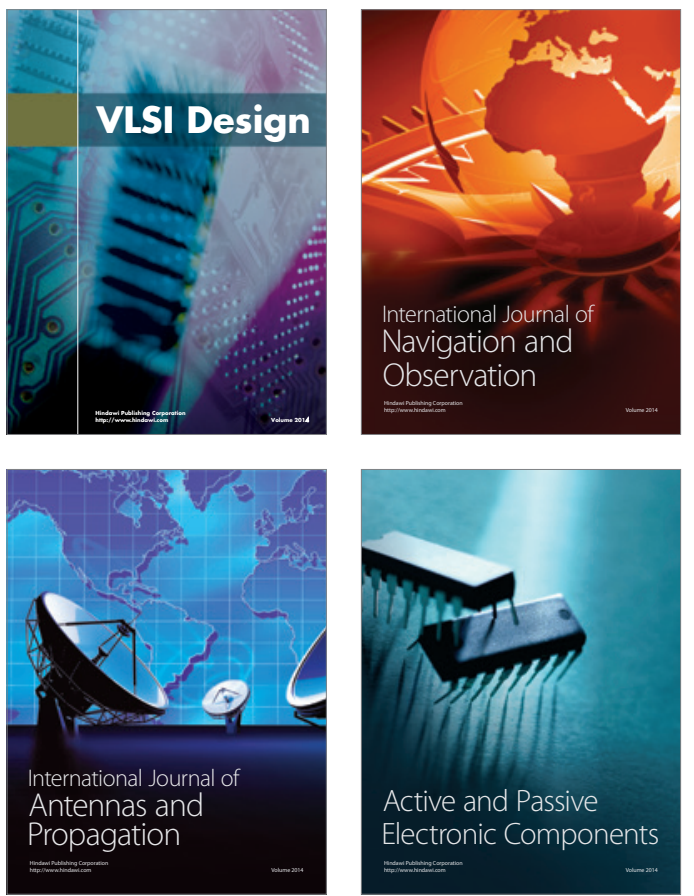
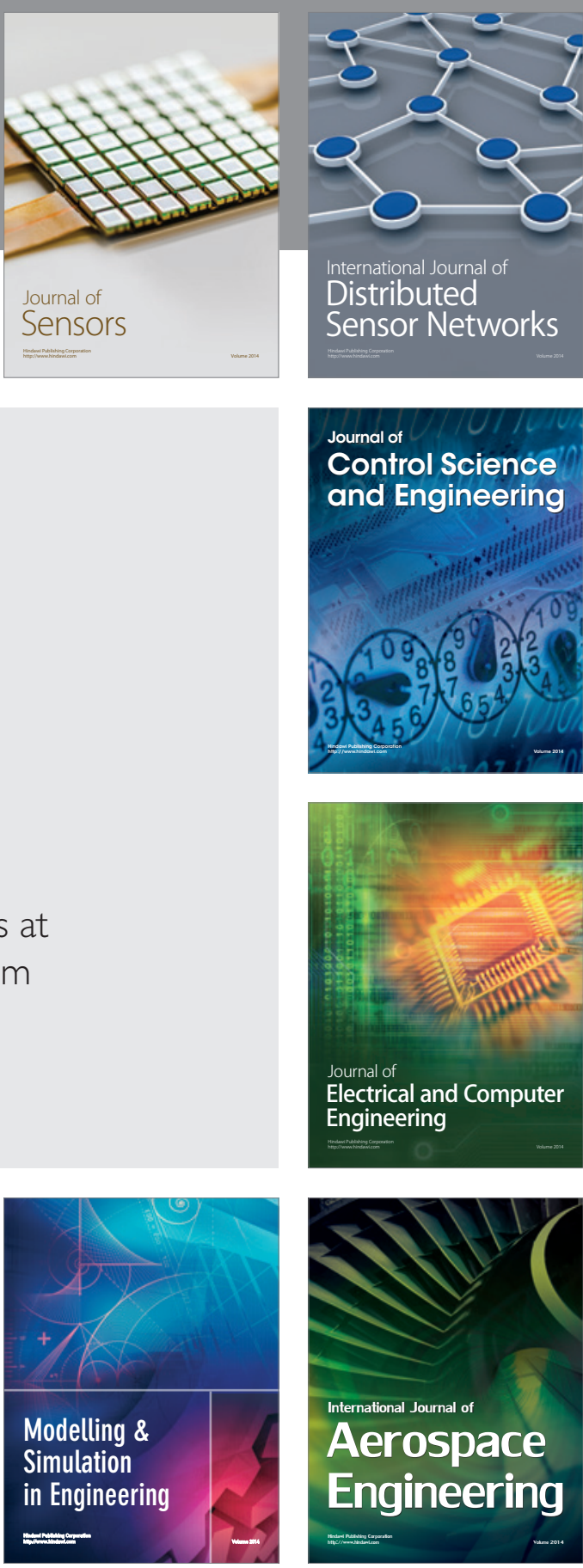

International Journal of

Distributed

Sensor Networks

$-$

Joumal of

Control Science

and Engineering
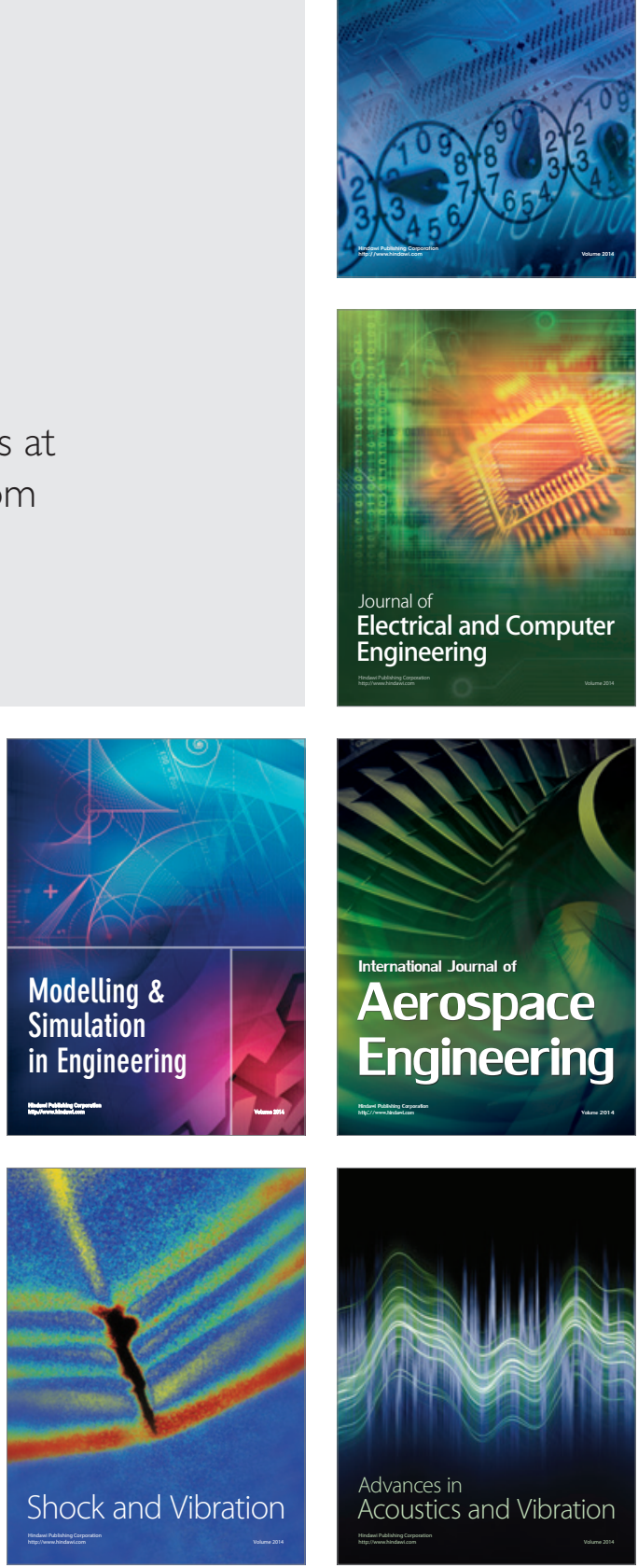